\title{
Constraining black carbon aerosol over Southeast Asia using OMI aerosol absorption optical depth and the adjoint of GEOS-Chem
}

\section{Zhang et al.}

Correspondence to: D. K. Henze (daven.henze@ colorado.edu) 
(a) MISR AOD

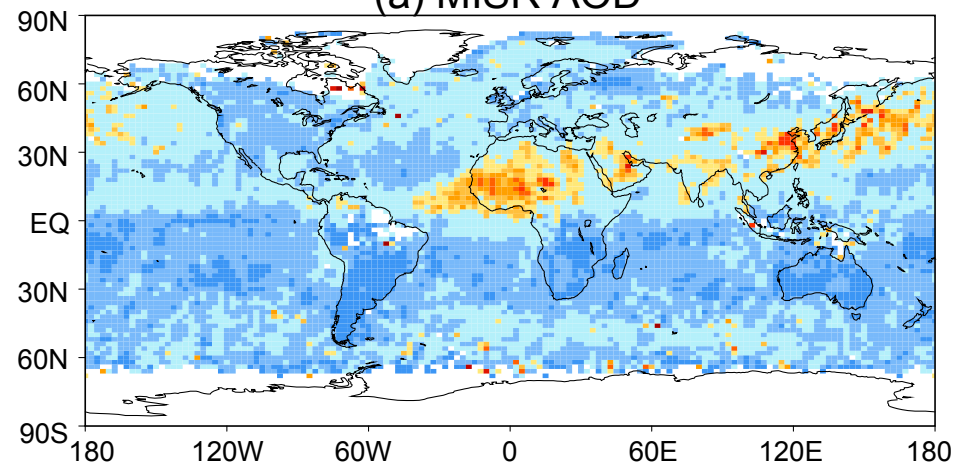

(b) GC-STD Dust AOD

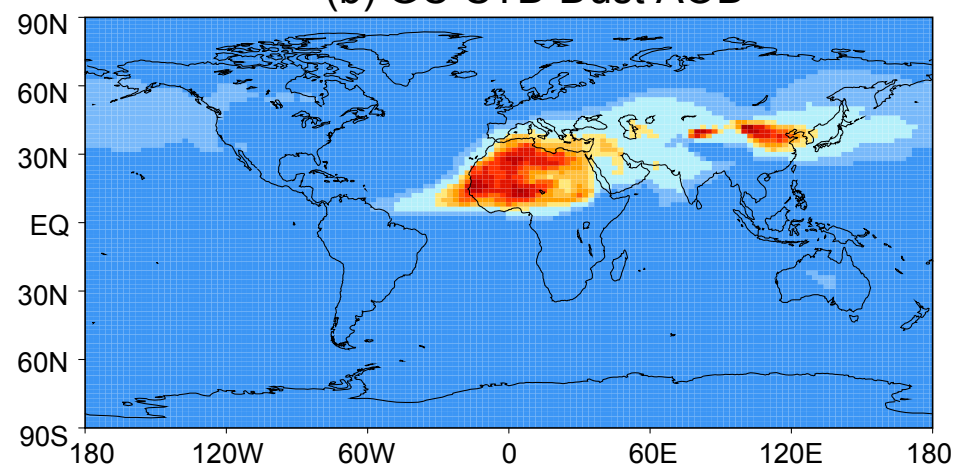

(c) New PSD Dust AOD

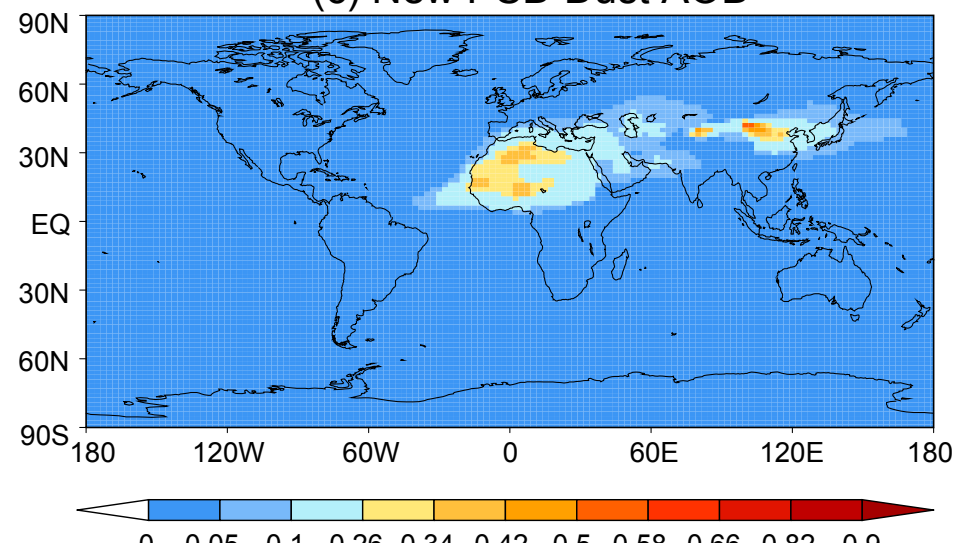

$\begin{array}{lllllllllll}0 & 0.05 & 0.1 & 0.26 & 0.34 & 0.42 & 0.5 & 0.58 & 0.66 & 0.82 & 0.9\end{array}$ (d) GC-STD minus MISR

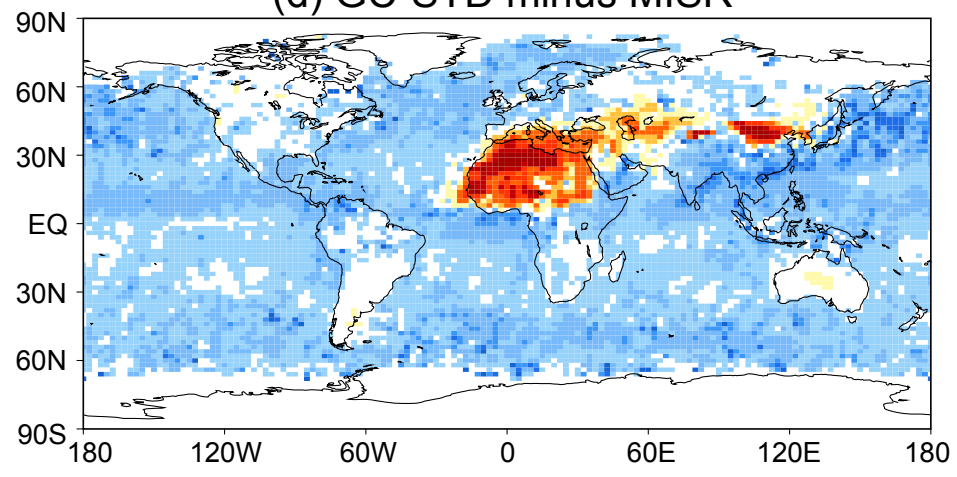

(e) New PSD minus MISR

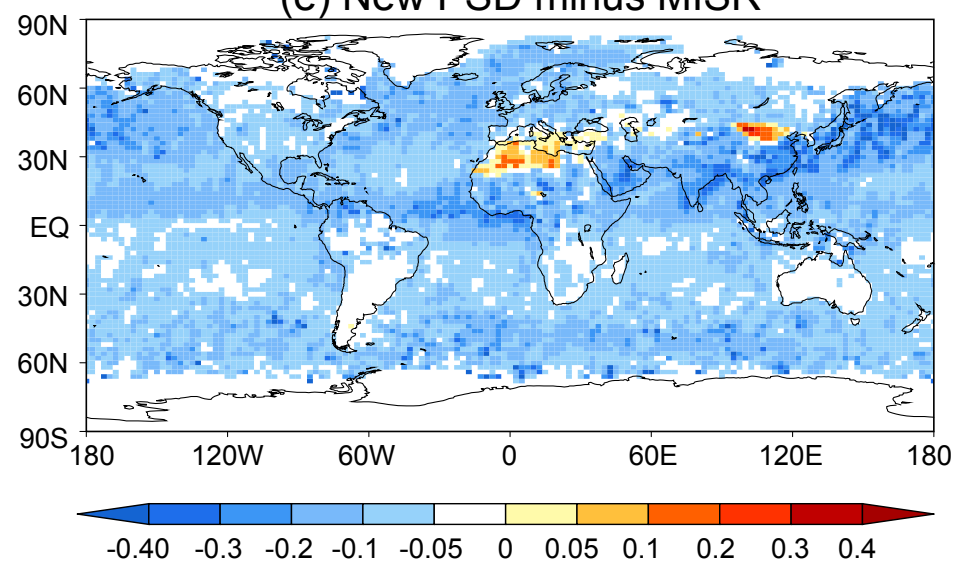

Fig. S1: Comparisons of MISR AOD and GEOS-Chem dust AOD for April 2006.

(a) MISR AOD;

(b) GEOS-Chem dust AOD with standard dust scheme;

(c) GEOS-Chem dust AOD with new PSD scheme;

(d) GEOS-Chem dust AOD with standard dust scheme minus MISR AOD;

(e) GEOS-Chem dust AOD with new PSD scheme minus MISR AOD 